\title{
Bölge Büyütmeli ve Kümeleme Tabanlı Yöntemler ile 3 Boyutlu Nokta Bulutlarının Bölütlenmesi
}

\author{
Hüseyin Bozkurt ${ }^{1}$, Rifat Kurban ${ }^{2 *}$ \\ ${ }^{1}$ Yozgat Bozok Üniversitesi, Sorgun Meslek Yüksekokulu, Bilgisayar Teknolojileri Bölümü, Yozgat, Türkiye (ORCID: 0000-0002-4500-4561) \\ 2 Kayseri Üniversitesi, Teknik Bilimler Meslek Yüksekokulu, Bilgisayar Teknolojieri Bölümü, Kayseri, Türkiye (ORCID: 0000-0002-0277-2210)
}

(International Symposium on Multidisciplinary Studies and Innovative Technologies (ISMSIT) 2021 - 21-23 October 2021)

(DOI: 10.31590/ejosat.1012062)

\begin{abstract}
ATIF/REFERENCE: Bozkurt, H., Kurban, R. (2021). Bölge Büyütmeli ve Kümeleme Tabanlı Yöntemler ile 3 Boyutlu Nokta Bulutlarının Bölütlenmesi. Avrupa Bilim ve Teknoloji Dergisi, (29), 99-104.

\section{$\ddot{O} \mathbf{z}$}

Endüstri 4.0 ve nesnelerin interneti yaklaşımı ile birçok sektörde geleneksel otomasyon yaklaşımı yerini görüntü işleme temelli yapay zekâ tekniklerine bırakmıştır. Teknolojik gelişmeler beraberinde yeni ihtiyaçları da getirmiştir. Bundan dolayı 2 boyutlu (2B) görüntü bölütleme problemlerinin yerini artık 3 boyutlu (3B) nokta bulutu bölütleme problemleri almıştır. 3B nokta bulutları görüntü işleme teknikleri olmaksızın makineler için bir anlam ifade etmez. Verilerin amaca uygun olarak işlenmesi ve sonrasında yorumlanması gerekir. Bu çalışması amacı, açık kaynak kodlu nokta bulutu kütüphanesi (PCL)'nin içerdiğgi 3B nokta bulutu bölütleme yöntemlerinin tanıtılması ve birbirleri ile farklı kriterlere göre kıyaslanmasıdır. Buna ek olarak, bu yöntemlerin varsayılan parametre değerlerinde değişiklikler yapılarak daha iyi sonuçların elde edilmesi amaçlanmıştır. Tüm yöntemler, varsayılan parametre değerleri ve belirlenen yeni parametre değerleri ile test edilerek farklı kriterlere göre kendi içinde ve diğerleri ile kıyaslanmıştır. Gerçekleştirilen deneylerde, bölge büyütmeli bölütleme yöntemlerinin bölütleme başarısının yüksek olduğu görülmüşsür. Ayrıca küme tabanlı bölütleme yöntemi olan öklid küme çıkarımı yönteminin ise diğer yöntemlere göre daha hızlı sonuç ürettiği görülmüştür.
\end{abstract}

\section{Segmentation of 3-Dimensional Point Clouds with Region-Growing and Clustering Based Methods}

\begin{abstract}
By using Industry 4.0 and the Internet of Things approaches, the traditional automation systems in many sectors have left its place to artificial intelligence techniques based on image processing. Technological developments have brought with new requirements and needs. Therefore, 2-dimensional (2D) image segmentation problems have now been replaced by 3-dimensional (3D) point cloud segmentation problems. 3D point clouds are meaningless to machines without image processing techniques. The visual data must be processed and then analysed. The aim of this study is to introduce the 3D point cloud segmentation methods included in the opensource point cloud library (PCL) and compare them with each other according to different criteria. In addition, it is aimed to obtain better results by making changes in the default parameter values of these methods. All methods are tested with the default parameter values and the optimized parameter values and compared within themselves and with others according to different criteria. In the experiments, it was observed that the segmentation success of the region augmentation segmentation methods is higher than others. In addition, it is seen that the Euclidean cluster extraction method, which is a cluster-based segmentation method, produces faster results than other methods.
\end{abstract}

Keywords: Point cloud library, 3D point clouds segmentation, 3D sensors.

* Sorumlu Yazar: Kayseri Üniversitesi, Teknik Bilimler Meslek Yüksekokulu, Bilgisayar Teknolojileri Bölümü, Kayseri, Türkiye, ORCID: 00000002-0277-2210, rifatkurban@kayseri.edu.tr 


\section{Giriş}

Günümüz teknolojisinde birçok uygulama alanı bulunan görüntü işleme yöntemlerinin giriş verisi olan görüntülere, farklı metotların uygulanabilmesi için ön işlemlere tabi tutulmaları gerekmektedir[1]. Son yıllarda gelişen teknoloji ile görüntü işleme üzerine yapılan çalışmaların sayısı ve kaliteleri artmıştır. Birçok sektörde görüntü işleme sayesinde insan eli değmeden makineler ile gerekli işlemler yapılmakta olup teknolojik gelişimler beraberinde yeni ihtiyaçları da getirmiştir. Teknolojinin gelişmesi ile $2 \mathrm{~B}$ görüntülerin yerini artık $3 \mathrm{~B}$ görüntüler almıştır[2]. 2B görüntü işleme bazı alanlarda yetersiz kalmış olup teknolojinin gelişmesi ile 3B görüntülerin işlenmesi kaçınılmaz olmuştur. Özellikle LIDAR ve Microsoft Kinect algılayıcılar ile 3B nokta bulutları farklı amaçlar için kolaylıkla elde edilebilmektedir. Nokta bulutu verilerini işlemek için bir kütüphaneye ihtiyaç duyulmaktadır. PCL 2011 yılında tanıtılmıştır[3]. Bu kütüphane; 3B algılama, işleme ve farlı birçok işlem için son teknoloji algoritmalar içerir. Donanım ve PCL'nin gelişimi ile nokta bulutlarının işlenmesi, diğer alanlarda olduğu gibi robotik alanında da oldukça fazla ilerleme kaydetmiştir.

Nokta bulutlarının ön ve arka kısım olarak bölütlenmesi 3B nokta bulutu işlemede bir temel adımdır. Verilen nokta bulutu için hedeflenen bölütleme işlemi, benzer karakteristiği olan noktaları homojen bölgelere kümeleme işlemidir. $\mathrm{Bu}$ ayrılmış alanlar anlamlı olmalıdır. Bölütleme işlemi sahne verilerini; konumlandırma, nesneleri tanıma, sınıflandırma ve özellik çıkarma gibi farklı yönleriyle analiz ederek yardımcı olabilir. Bilgisayar grafiklerinde 3B modelleri fonksiyonel olarak anlamlı bölgelere ayırmak için oldukça yoğun araştırmalar yapılmaktadır. Bunun genel yolu, girdi verisinden bir graf oluşturmak ve normal yön, pürüzsüzlük ya da içbükey sınırlar boyunca olan bilgileri kullanarak bir bölütleme yapmak için grafi kümelemektir. Bununla birlikte dışbükey ayrışma, sınır analizi, hiyerarşik kümeleme, bölge büyümeli ve hayali kümeleme gibi problemler için çeşitli metotlar önerilmiştir[4].

3B nokta bulutlarının bölütlenmesi için önerilen kategorize edilmiş 5 adet yöntem vardır. Bunlar; kenar tabanlı yöntemler, bölge tabanlı yöntemler, nitelik tabanlı yöntemler, model tabanlı yöntemler ve graf tabanlı yöntemler. Kenar tabanlı yöntemde, kenarlar nesnelerin karakteristiğini tanımlar. $\mathrm{Bu}$ yöntem, bölütlenmiş bölgeleri elde etmek için nokta bulutundaki birçok sınırı belirler. $\mathrm{Bu}$ yöntemlerin ana prensibi noktaları hızlı bir biçimde yoğunluğa göre yerleştirmeleridir[4]. Bölge tabanlı yöntem, komşuluk bilgilerini kullanarak yakındaki benzer özelliklere sahip noktaları birleştirir ve dolayısıyla bölgeler arasındaki farklılığı bulur. Kenar tabanlı yönteme göre daha doğru çalışır ve kendi arasında aşağıdan yukarı ve yukarıdan aşağı olmak üzere ikiye ayrılır. Nitelik tabanlı yöntem, ayrı iki adım içermektedir. Birinci adımda nitelik hesaplama, ikinci adımda ise nokta bulutları hesaplanmış niteliklere göre kümeleme yapılır. Model tabanlı yöntem, ilkel şekilleri (örneğin küre, koni, düzlem ve silindir gibi), noktaları gruplandırma için kullanır. Aynı matematiksel sunumda olan noktalar bir bölümde gruplandirılır. En iyi bilinen algoritma RANSAC'dır[5]. RANSAC güçlü bir modeldir ve matematiksel özellikleri olan düz çizgileri, daireleri belirler. 3B nokta bulutu bölütleme için sonraki birçok çalışmaya bu ilk algoritma miras olmuştur. Graf tabanlı yöntemlerde, her bir köşe verideki bir noktaya karşılık gelir ve komşu noktaların belirli çiftlerine kenarlar bağlanır. En çok bilinen algoritmalardan birisi $\mathrm{KNN}(k$ en yakın komşu)'dur[6].

3B algılayıcılardan elde edilen nokta bulutlarının bölütlenme problemlerin çözümü ve mevcut yöntemlerin farklı karakteristikteki veri kümeleri üzerinde kıyaslanması için bu çalışma kapsamında PCL'nin ihtiva ettiği; nokta bulutlarının süpervoksel içine kümelenmesi, bölge büyütmeli bölütleme, renk tabanlı bölge büyütmeli bölütleme, öklid küme çıkarımı ve koşullu öklid kümeleme olarak isimlendirilen 5 adet bölütleme yönteminin hem belirlenen kriterlere göre kıyaslanması hedeflenmiştir. PCL'de bölütleme için geliştirilen ve bahsedilen 5 yöntemin kendi içerisinde farklı parametre değerleri ile seçilen farklı özellikteki veri setleri üzerinde deneyler yapılarak optimum parametre değerleri bulunmuştur. Sözü geçen 5 yöntemin varsayılan ve deneyler sonucu belirlenen yeni parametre değerlerine göre birbirleri arasında, seçilen farklı özellikteki veri setleri üzerinde bölütleme işlemi yapılarak, program çalışma süreleri ve bölütleme yüzdesi üzerine kıyaslamalar yapılmıştır.

\section{Materyal ve Metot}

\subsection{PCL Kütüphanesi}

PCL, 3B nokta bulutu işleme için tamamen şablonlardan oluşan modern bir C++ kütüphanesidir ve 2011 yılında bir açıkkanynak kodlu proje olarak başlamıştır. Kütüphanede yer alan birçok matematiksel operatörler lineer cebir için açık kaynaklı şablon kütüphanesi olan Eigen temeli üzerine kurulmuştur. Buna ek olarak paralel programlama için PCL OpenMP ve çok çekirdekli paralelizasyon için Intel Threading Buildings Blocks (TBB) kütüphanesi destek sunmaktadır. PCL, hızlı k-yakın komşuluk araştırma temel operatörleri için FLANN (Fast Library for Approximate Nearest Neighboor - yaklaşık en yakın komşuluk için hızlı kütüphane) kütüphanesinden destek almaktadır. Ayrıca PCL Kütüphanesi nokta bulutlarının görüntülenmesi için VTK (Visualization Toolkit: Görselleştirme araç takımı) kütüphanesini kullanmaktadır. PCL kütüphanesi Windows, MacOS ve Linux işletim sistemleri üzerinde çalışabilmektedir[3].

\subsection{Bölütleme Yöntemleri}

Bölütleme algoritmalarının amacı, görüntü içerisindeki pikselleri gruplandırarak anlamlı bölgelere ayırmaktır. $\mathrm{Bu}$ kısımda, öncelikle çalışmada kullanılan ve PCL'de mevcut olan nokta bulutlarının süpervoksel içine kümelenmesi, bölge büyütmeli bölütleme, renk tabanlı bölge büyütmeli bölütleme, öklid küme çıkarımı, koşullu öklid kümeleme olarak isimlendirilen 5 farklı bölütleme algoritması anlatılmıştır.

\subsubsection{Süpervoksel İçine Kümelenme Algoritması}

Süperpikseller görüntüyü düşük seviye özellikleri temel alarak çok sayıda bölütleme işlemi ile ayrılan küçük bölgeler ile oluşur ve istenen sonuç dikkate alınarak düğüm sayısı indirgenir. Nesne sınırlarını ihlalden kaçınmak oldukça önemlidir, ihlal durumunda daha sonra kullanılacak sınıflandırıcının doğruluğu azalarak başarısız olacaktır. Sınıflandırcı doğru bir çıktıyı yönetse bile, piksel seviyesindeki son bölütleme zorunlu olarak hatalar içerecektir. Voksel bulut bağlantı bölütleme metodu (voxel cloud connectivity segmentation), süpervoksel olarak bilinen 3B nokta bulutu verilerin hacimsel olarak çok sayıda 
bölütlenmesi işlemidir. Süpervoksellerin iki önemli özelliği vardır. Birincisi, onlar 3B alan karşısında eşit olarak dağıtılırlar. İkincisi, vokseller uzaysal olarak bağlı olmadığı müddetçe onların sınırları kesişemez.

\subsubsection{Bölge Büyütmeli Bölütleme Algoritması}

Bölge büyütmeli bölütleme algoritmasının amacı pürüzsüzlük kısıtlaması açısından yeterince yakın noktaları birleştirmektir. Sonuçta bu algoritmanın çıktısı aynı yüzey özelliklerine sahip nokta bulutlarından oluşan kümelerin bir araya gelmesiyle oluşan küme topluluklarıdır. $\mathrm{Bu}$ algoritmanın temeli normaller arasındaki açıların karşılaştırılmasına ve eğrilik farklarına dayanır. Algoritma çalışmasında ilk olarak noktalar eğrilik değerlerine göre sıralanır. Bu gereklidir, çünkü bölge büyütme minimum eğrilik değerine sahip noktadan başlar. Minimum eğrilik değerine sahip nokta düz alanda bulunur ve düz alanda olan büyüme bölütleme sayısını azaltmaya izin verir. Nokta bulutunda etiketsiz nokta kalmayana kadar algoritma noktaları minimum değerli ile toplar ve bölge büyütmeye başlar.

\subsubsection{Renk Tabanlı Bölge Büyütmeli Bölütleme Algoritması}

$\mathrm{Bu}$ algoritma, bölge büyütmeli bölütleme algoritması ile aynı kavramları temel almıştır. Ancak ikisi arasında iki temel fark bulunmaktadır. Bunlardan birincisi normaller ve eğrilikler yerine RGB renklerini kullanıyor olmasıdır. İkincisi ise üst ve alt bölütleme için birleştirme algoritmasını kullanıyor olmasıdır. Bölütlemeden sonra yakın renkli kümelerin birleştirilmesi için bir girişim yapılır. Ortalama renkten küçük bir fark1 olan yani ortalama rengi benzer olan iki komşu küme birleştirilir. Daha sonra ikinci birleştirme adımı gelir. Bu adım esnasında tek olan tüm kümeler noktaların numarası ile doğrulanır. Şayet bu numara kullanıcının tanımladığı değerden küçük ise, güncel küme en yakın komşu küme ile birleştirilir[7]. Yani kümeler belirlenen minimum kümeden küçük ise komşuları ile birleştirilir.

\subsection{4. Öklid Küme Çıkarımı Algoritması}

Öklid küme çıkarımı algoritması, mevcut PCL bölütleme algoritmaları içerisinde en basit olanıdır. İki nokta arasındaki mesafeyi ölçer. Şayet eşik değerden küçük ise, her ikisinin de aynı küme içerisine dahil olduğu düşünülür. Bir nokta küme için seçilen olarak işaretlenir. Daha sonra bir virüs gibi yeterince yakınında olan tüm noktalara dağılır ve olanlardan daha fazla noktaya eklenecek yeni nokta kalmayana kadar yayılır. Daha sonra yeni bir küme başlatılır ve bu prosedür kalan işaretlenmemiş noktalarla tekrar başlar[10].

\subsubsection{Koşullu Öklid Kümeleme Algoritması}

Koşullu öklid kümeleme algoritması, öklid küme çıkarımı algoritması ile standart olarak aynı şekilde çalışır, ancak bir istisnai durum vardır. Mesafe kontrolünün dışında noktalar özel bir tanışmaya ihtiyaç duyarlar, onlar için özel gereksinim bir kümeye eklenmektir. Bu şart kullanıcı tarafından belirtilir. Noktaların her bir parçası için (birincisi o anda işlenen kaynak noktadır, ikincisi ise önceden test edilen eski bir komşu olan aday noktadır) özel işlevi olan bir fonksiyon çağırılır. Bu fonksiyonun özel bir işareti, imzası vardır ve şu görevleri yapar: 1) İki noktanın bir kopyasını alır, böylelikle istenilen test gerçekleştirilebilir, 2) uzaklığın karesini alır. Bunları yaptıktan sonra doğru veya yanlış şeklinde bir değer döndürür. Şayet bu değer "doğru" ise, aday nokta kümeye eklenebilir. Eğer dönen değer "yanlış" ise aday nokta uzaklık testini geçse bile kümeye eklenmez[8].

\subsection{Kalite Metrikleri}

Bölütleme yöntemleri kullanılarak test verileri üzerinde işlemler yaparken geçen işlem süreleri ve test verilerinin bölütleme işlemi sonrası çıtı görüntüde nesnelerin görsel olarak bölütleme yüzdeleri kalite metriklerini oluşturmaktadır. Test verilerinin bahsedilen yöntemlerle bölütleme işleminin yapılması ile program tarafından mili saniye olarak hesaplanan süre, işlem süresini vermektedir. Program çalışma süresi deneylerde "PÇS" olarak gösterilecektir. İşlem süresini bulmak için PCL'de mevcut olan TicToc sınıfı kullanılmıştır.

Test verileri üzerinde bahsedilen yöntemlerle bölütleme işlemleri yapılmış olup, orijinal veri seti ile bölütlenmiş veri setindeki nesne sayılarında bir oranlama işlemi yapılmıştır. Örneğin orijinal veri setinde 5 adet nesne varsa ve bu bölütleme işleminden geçtikten sonra bölütlenerek belirlenmiş nesne sayısı 5 ise bölütleme oranı \%100'dür ve algoritma o veri seti için başarılıdır kabul edilmektedir. Burada orijinal veri setindeki toplam nesne sayısı "TNS", bölütlenmiş veri setindeki nesne sayıs1 ise "BNS" ve bunların bölütleme yüzdesi ise "BY" ile ifade edilmiştir. Bölütleme yüzdesinin nasıl hesaplandığı (1) numaralı denklemde verilmiştir.

$$
B Y=(B N S / T N S) * 100
$$

\subsection{Deneylerde Kullanılan Veri Kümeleri}

Çalışma kapsamında yöntemlerin literatür ile bütünlüğünü daha kolay sağlamak amacıyla 3B nokta bulutu ile alakalı daha önceki farklı çalışmalarda kullanılan bazı test verileri seçilmiştir. Toplamda 35 adet farklı test verisi üzerine çalışılmış olup 25 tanesi renk verisi içeren, 5 tanesi renk verisi içermeyen ve 5 tanesi de intensity (yoğunluk) verisi içeren $3 \mathrm{~B}$ nokta bulutu test verileridir. Deneyler, Microsoft Visual Studio 2012 platformu üzerinde yapılmıştır. Test verilerinden 25 tanesi RGBD 3B veri setidir ve IROS (Intelligent Robots and Systems) 2012 Uluslararası Konferansında Richtsfeld Andreas ve arkadaşları tarafindan kendi çalışmalarında kullanılarak sunulmuştur. Ayrıca bu 25 adet RGBD test verisi Kinect V1 cihazı ile taranarak elde edilmiştir[9]. Sözü geçen test verilerinden bir kesit Şekil 1'de verilmiştir. 

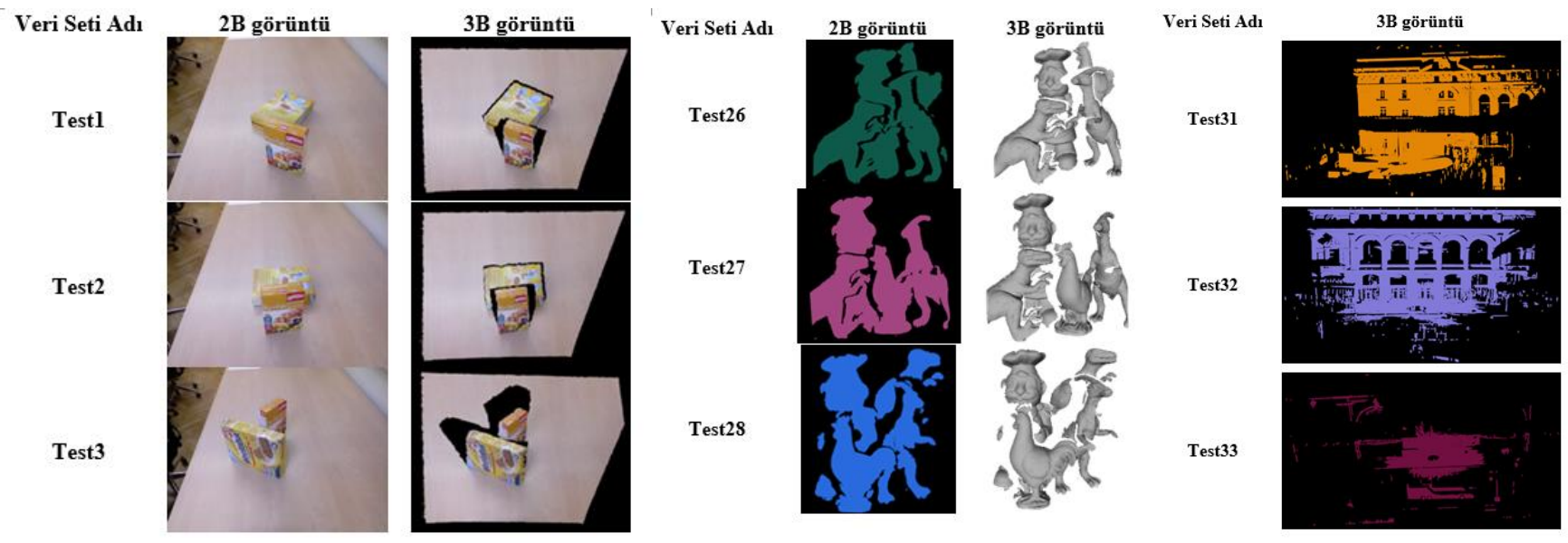

Şekil 1. Kullanılan veri setlerinden belirli örneklerin $3 B$ gösterimleri.

\section{Araștırma Sonuçları ve Tartıșma}

3B nokta bulutlarının bölütlenmesi için PCL'ye ait 5 farklı bölütleme yöntemi tanıtılmış ve bu yöntemler kullanılarak 35 adet test verisi üzerinde bölütleme işlemleri yapılmıştır. Deneyler yapılırken varsayılan parametre değerleri kullanılmış ve daha iyi sonuçlar elde edebilmek için bazı yöntemlere yeni parametre değerleri belirlenmiştir. Hem varsayılan hem de belirlenen parametre değerleri için toplamda 350 adet deney yapılmıştır. Yönemlerin varsayılan ve belirlenen parametre değerleri Tablo 1'de verilmiştir. Deneyler sonucu veri setindeki seçilmiş belirli örneklerin görsel bölütleme sonuçları Şekil 2'de verilmiştir. Deneylere ait sayısal sonuçlar ise Şekil 3'te görselleştirilmiştir.

Tablo 1. Yöntemlerin varsayllan parametre değerleri ve belirlenen parametre değerleri.

\begin{tabular}{|c|c|c|}
\hline Yöntem & $\begin{array}{l}\text { Varsayılan Parametre } \\
\text { Değeri }\end{array}$ & $\begin{array}{l}\text { Belirlenen Parametre } \\
\text { Değeri }\end{array}$ \\
\hline Süpervoksel & $\begin{array}{l}\text { voxel_resolution }=0.008 \\
\text { seed_resolution }=0.1 \\
\text { color_importance }=0.2 \\
\text { spatial_importance }=0.4 \\
\text { normal_importance }=1.0\end{array}$ & $\begin{array}{l}\text { voxel_resolution }=0.008 \\
\text { seed_resolution }=0.3 \\
\text { color_importance }=0.2 \\
\text { spatial_importance }=1.0 \\
\text { normal_importance }=3.0\end{array}$ \\
\hline Bölge & setMinClusterSize $=50$ & setMinClusterSize $=100$ \\
\hline Büyütmeli & $\begin{array}{l}\text { setMaxClusterSize }=1000000 \\
\text { setNumberOfNeighbours }=30\end{array}$ & $\begin{array}{l}\text { setMaxClusterSize }=1000000 \\
\text { setNumberOfNeighbours }=200\end{array}$ \\
\hline $\begin{array}{l}\text { Renk } \\
\text { Tabanlı } \\
\text { Bölge } \\
\text { Büyütmeli }\end{array}$ & $\begin{array}{l}\text { setDistanceThreshold }=10 \\
\text { setPointColorThreshold }=6 \\
\text { setRegionColorThreshold }=5 \\
\text { setMinClusterSize }=600\end{array}$ & $\begin{array}{l}\text { setDistanceThreshold }=10 \\
\text { setPointColorThreshold }=7 \\
\text { setRegionColorThreshold }=5 \\
\text { setMinClusterSize }=1700\end{array}$ \\
\hline $\begin{array}{l}\text { Öklid } \\
\text { Kümeleme }\end{array}$ & $\begin{array}{l}\text { ClusterTolerance }=0.02 \\
\text { setMinClusterSize }=100 \\
\text { setMaxClusterSize }=25000\end{array}$ & $\begin{array}{l}\text { ClusterTolerance }=0.02 \\
\text { setMinClusterSize }=100 \\
\text { setMaxClusterSize }=25000\end{array}$ \\
\hline $\begin{array}{l}\text { Koşullu } \\
\text { Öklid } \\
\text { Kümeleme }\end{array}$ & $\begin{array}{l}\text { setLeafSize }=10 \\
\text { setClusterTolerance }=500 \\
\text { setMinClusterSize }=\text { size } / 1000 \\
\text { setMaxClusterSize }=\text { size } / 5\end{array}$ & $\begin{array}{l}\text { setLeafSize }=10 \\
\text { setClusterTolerance }=500 \\
\text { setMinClusterSize }=\text { size } / 1000 \\
\text { setMaxClusterSize }=\text { size } / 5\end{array}$ \\
\hline
\end{tabular}

\subsection{Varsayılan Parametre Değerlerine Göre BY Grafiği Değerlendirmesi}

Renkli veriler için; öklid küme çıkarımı yöntemi diğerlerine göre daha başarılı iken, en başarısız yöntem noktaların süpervoksel içine kümelenmesi yöntemidir. Renksiz veriler için; renk tabanlı bölge büyütmeli bölütleme yöntemi diğerlerine göre daha başarılı iken, en başarısız yöntem öklid küme çıkarımıdır. Buna göre, varsayılan parametre değerleri kullanıldığında renkli ve renksiz ayrımı yapmadan tüm veri setleri için, renk tabanlı bölge büyütmeli bölütleme yöntemi daha başarılı olup, noktaların süpervoksel içine kümelenmesi yöntemi genellikle başarısızdır.

\subsection{Belirlenen Parametre Değerlerine Göre BY Grafiği Değerlendirmesi}

Renkli veriler için; bölge büyütmeli bölütleme yöntemi diğerlerine göre daha başarılı iken, en başarısız yöntem öklid küme çıkarımıdır. Renksiz veriler için; bölge büyütmeli bölütleme yöntemi diğerlerine göre daha başarılı iken, en başarısız yöntemin yine öklid küme çıkarımı yöntemi olduğu görülmüştür. Buna göre, belirlenen parametre değerleri kullanıldığında renkli ve renksiz ayrımı yapmadan tüm veri setleri için, bölge büyütmeli bölütleme yöntemi daha başarılı olup, öklid küme çıkarımı yöntemi genellikle başarısızdır.

\subsection{Varsayılan Parametre Değerlerine Göre PÇS Grafiği Değerlendirmesi}

Renkli veriler için; öklid küme çıkarımı yöntemi diğerlerine göre daha hızlı çalışmakta iken, en yavaş çalışan yöntem bölge büyütmeli bölütleme yöntemidir. Renksiz veriler için; öklid küme çıkarımı yöntemi diğerlerine göre daha hızlı çalışmakta iken, en yavaş çalışan yöntem bölge büyütmeli bölütlemedir. Intensity verisi içeren ver setlerinde sadece koşullu öklid kümeleme yöntemi bölütleme işlemi yapabilmektedir ve program çalışma süresi de oldukça makul seviyelerdedir. Buna göre, varsayılan parametre değerleri kullanıldığında renkli ve renksiz ayrımı yapmadan tüm veri setleri için, öklid küme çıkarımı yöntemi daha hızlı çalışmakta olup, bölge büyütmeli bölütleme yöntemi genellikle daha yavaş çalışmaktadır.

\subsection{Belirlenen Parametre Değerlerine Göre PÇS Grafiği Değerlendirmesi}

$\mathrm{Bu}$ grafikteki nicel değerler, varsayılan parametre değerlerine göre PÇS grafiğindeki değerler ile aynı olmasa da yöntemlerin PÇS sıralamaları tamamen aynıdır. Bu sıralamanın aynı olmasının sebebi ise; yapılan parametre değeri değişiklikleri yöntemlerin çalışma şekillerinde bir değişiklik yapmadığından dolayı PÇS değerlerine çok az etki etmiş olup, asıl etkiyi BY'lere yapmıştır. Çünkü parametreler, programın çalışmasından ziyade bölütlenecek kısımlarla doğrudan ilgilidir. 


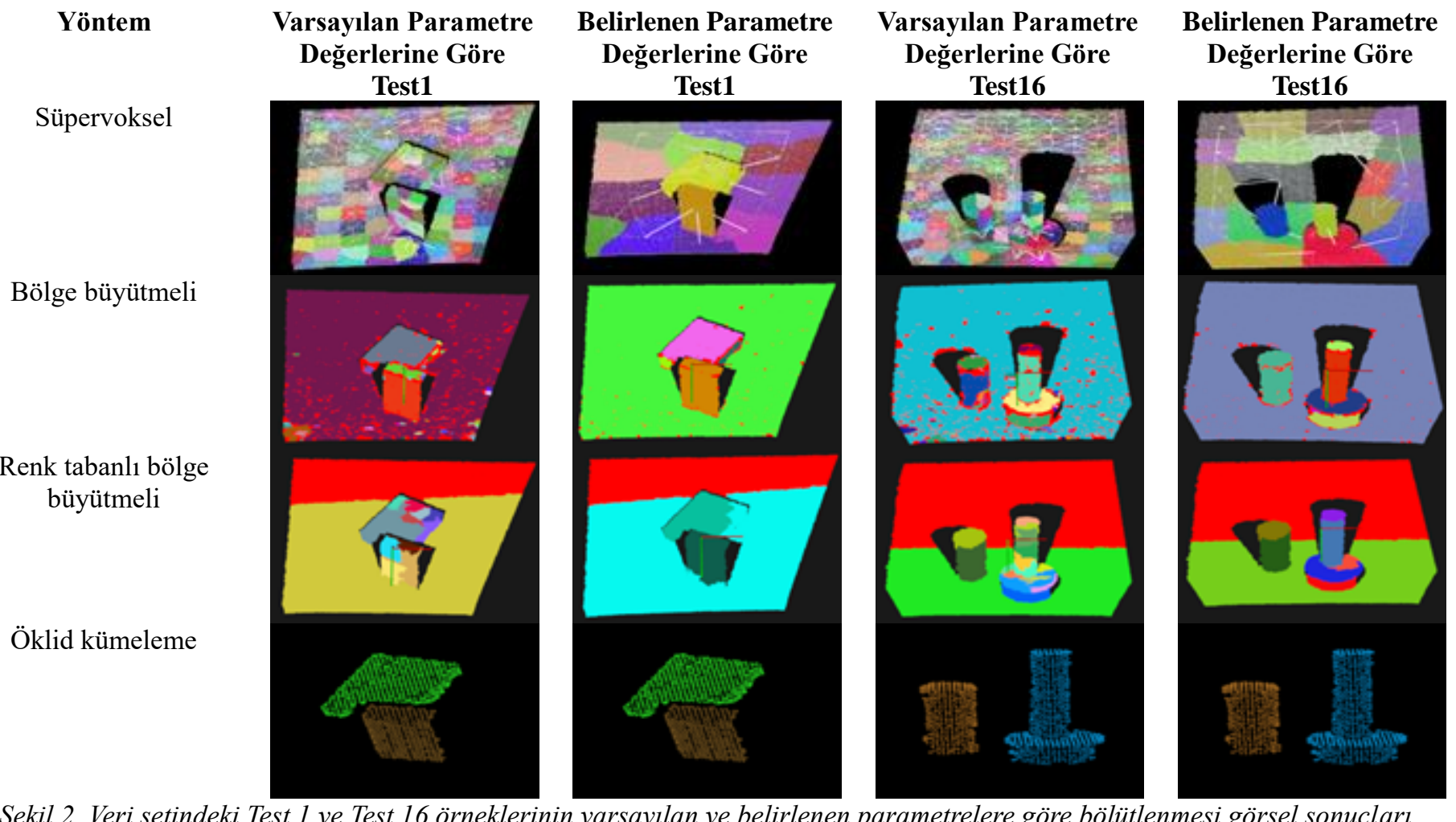

Şekil 2. Veri setindeki Test 1 ve Test 16 örneklerinin varsayılan ve belirlenen parametrelere göre bölütlenmesi görsel sonuçları.
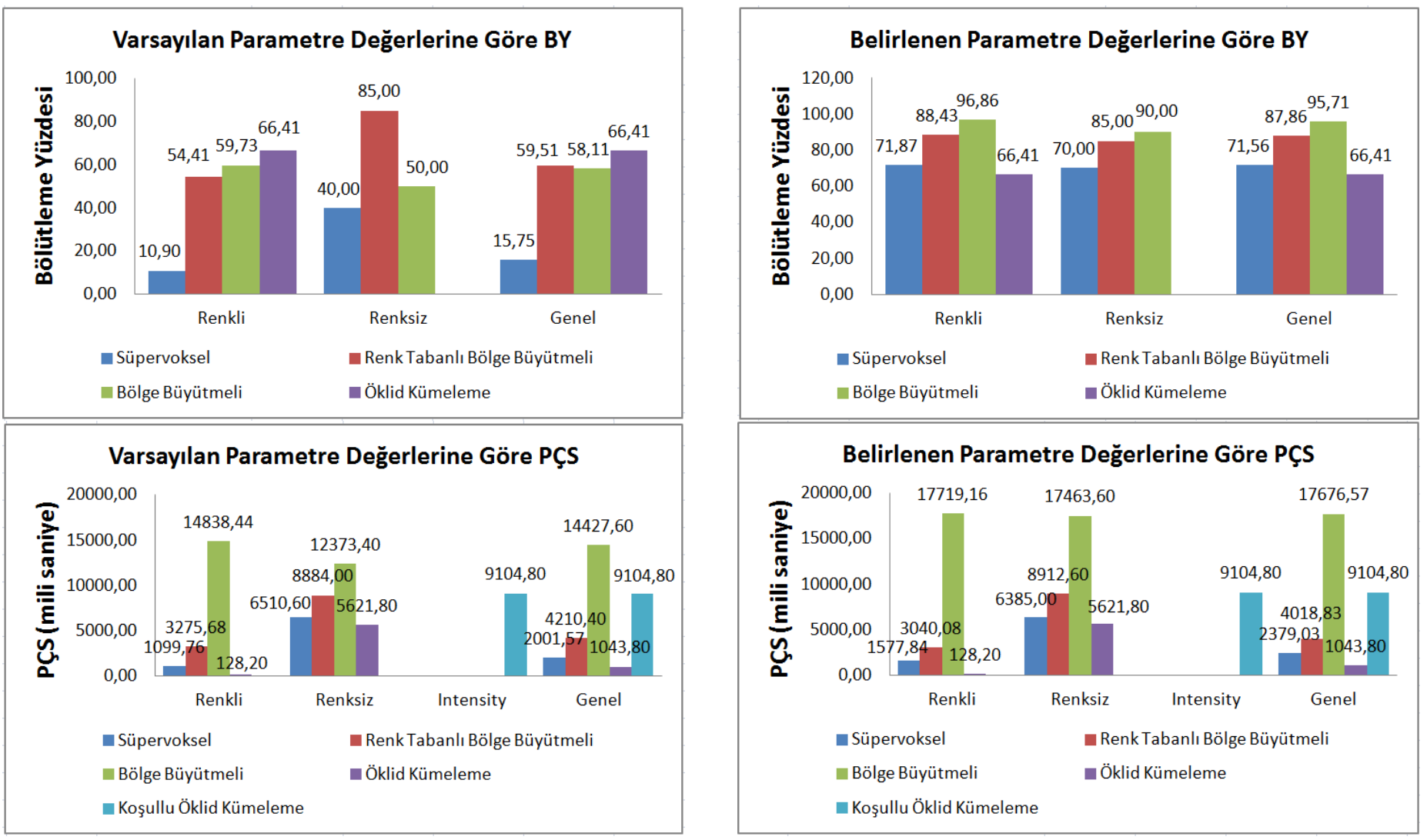

Şekil 3. Varsayılan ve belirlenen parametrelere göre bölütleme yöntemlerinin sayısal sonuçlarının karşılaştırılması. 


\section{Sonuç}

Elde edilen sonuçlar değerlendirildiğinde; 3B nokta bulutu bölütlemede PCL'nin ihtiva ettiği yöntemlerden yoğunluk (intensity) verisine sahip 3B nokta bulutu verilerini bölütleyebilen ve alanında tek olan yöntem, koşullu öklid kümeleme yöntemidir. Bu yöntem için bakıldığında, kullanılan veri setlerinin hafizada kapladığı alanın oldukça büyük olmasına rağmen, PÇS oldukça makul seviyelerdedir. Ayrıca bölütleme yüzdesi olarak en başarılı yöntemlerin, bölge tabanlı bölütleme yöntemlerinden olan bölge büyütmeli bölütleme ve renk tabanlı bölge büyütmeli bölütleme yöntemleri olduğu görülmüştür. Bunun yanı sıra hızlı sonuç üretme yönünden en başarılı yöntemlerin, küme tabanlı bölütleme yöntemlerinden olan öklid küme çıarımı yöntemi ve noktaların süpervoksel içine kümelenmesi yöntemi olduğu görülmüştür.

$\mathrm{Bu}$ çalışma kapsamında, bölütleme işleminde başarıyı belirleyen 2 adet kriter vardır. Bunlar, bölütleme yüzdesi (BY) ve program çalışma süresidir (PÇS). BY değeri; tamamen algoritma adımlarına, veri setine ve parametre değerlerine bağlı olup bilgisayar donanımı ile doğrudan alakası yoktur. PÇS değeri ise; algoritma adımlarına, veri setine, parametre değerlerine ve doğrudan bilgisayar donanımına bağlıdır. Bundan dolayı, bölütleme yönteminin başarılı olması öncelikle BY değerinin yüksek olmasına bağlıdır. İkinci olarak PÇS değeri gelir ki; yöntemlerin PÇS değerlerine bakıldığında çok fazla fark olmamakla birlikte, daha gelişmiş bilgisayar donanımları ile bu küçük farklar telafi edilebilir seviyededir ve bundan dolayı başarıyı etkileyen ikinci kriterdir.

$\mathrm{Bu}$ bilgiler 1şı̆̆ında; yapılan deneyler sonucu varsayılan parametre değerlerine göre, renk tabanlı bölge büyütmeli bölütleme yönteminin oldukça başarılı olduğu görülmektedir. Belirlenen parametre değerlerine göre ise, bölge büyütmeli bölütleme yönteminin oldukça başarılı olduğu görülmektedir.

\section{Teşekkür}

$\mathrm{Bu}$ çalışma; Erciyes Üniversitesi Bilimsel Araştırma Projeleri Birimi tarafindan FYL-2014-5352 kodlu proje ile desteklenmiştir.

\section{Kaynakça}

1. Aslantaş, V., Bendeş, E., Kurban, R., \& Toprak, A. N. (2011). Çoklu Algılayıcılardan Alınan Görüntülerde Eşleştirme Yöntemlerinin Karşılaştırılması. ElektrikElektronik ve Bilgisayar Seтроzуити, 110-114.

2. Sertalp, E., (2010). Görsel İletişimde Üç Boyut Algısı; Hologram Tekniği Ve Bu Teknolojinin Eğitim Ortamına Aktarılması. Gazi Üniversitesi, Eğitim Bilimleri Enstitüsü, Doktora Tezi, Ankara, $228 \mathrm{~s}$.

3. Rusu, R. B., \& Cousins, S. (2011, May). 3d is here: Point cloud library (pcl). In 2011 IEEE international conference on robotics and automation (pp. 1-4). IEEE.

4. Nguyen, A., \& Le, B. (2013, November). 3D point cloud segmentation: A survey. In 2013 6th IEEE conference on robotics, automation and mechatronics (RAM) (pp. 225230). IEEE.

5. Fischler, M. A., \& Bolles, R. C. (1981). Random sample consensus: a paradigm for model fitting with applications to image analysis and automated cartography. Communications of the ACM, 24(6), 381-395.

6. Golovinskiy, A., \& Funkhouser, T. (2009, September). Mincut based segmentation of point clouds. In 2009 IEEE 12th International Conference on Computer Vision Workshops, ICCV Workshops (pp. 39-46). IEEE.

7. Region growing rgb segmentation (2015,Mayis). Erişim adresi: http://pointclouds.org/documentation/tutorials/region _growing_rgb_segmentati on.php\#region-growing-rgbsegmentation.

8. OpenNI tutorial 3: Cloud processing (advanced)\#Conditional (2015,Mayıs) Erişim adresi:http://robotica.unileon.es/mediawiki/ index.php /PCL/ OpenNI_tutorial_3:_Cloud_processing_(advanced)\#Conditi onal.

9. Richtsfeld, A., Mörwald, T., Prankl, J., Zillich, M., \& Vincze, M. (2012, October). Segmentation of unknown objects in indoor environments. In 2012 IEEE/RSJ International Conference on Intelligent Robots and Systems (pp. 47914796). IEEE.

10. OpenNI_tutorial_3:Cloud_processing(advanced)\#Euclidean (Nisan,2015) Erişim adresi: http://robotica.unileon.es/mediawiki/ index.php/PCL/OpenNI_tutorial_3:Cloud _processing(advanced)\#Euclidean. 